\title{
Women's Leader Development Programs: Current Landscape and Recommendations for Future Programs
}

\author{
Taylor D. Kimball \\ Claremont Graduate University \\ Rebecca J. Reichard \\ Claremont Graduate University \\ Emily L. Chan \\ Claremont Graduate University
}

The gender gap in leadership positions is unjust and unproductive. In this paper, we focus on one solution - leader development. We leverage a content analysis of the top U.S. women's leader development programs (WLDPS) and literature on women's leadership and leader development. We provide seven evidence-based recommendations for WLDPs including: identify measurable objectives, increase access for emerging leaders, cultivate a paradox mindset around leader and gender identity, leverage experiential learning, expand networks, educate about second-generation gender bias, and align evaluations. We urge administrators to adopt our recommendations as one piece of a systematic effort to pursue gender parity in leadership.

Keywords: women's leadership, women's leader development, leadership training, leadership development, second generation gender bias

\section{INTRODUCTION}

As of 2019, women make up around $47 \%$ of the U.S. workforce, but this percentage dramatically decreases when examining executive-level positions. Women hold only $34 \%$ of all senior management positions, $21 \%$ of C-suite positions, and a mere $6.2 \%$ of CEO positions at S\&P 500 companies (Catalyst, 2020). Although women only began entering the workforce en masse less than fifty years ago, advocates have long hoped that once the pipeline of women in leadership started flowing, the gender disparity seen among top leadership would similarly decrease. However, given the continued lack of women leaders at top organizational levels, this result will not occur without additional interventions, such as leader development.

Leadership development is a multi-billion-dollar industry (Forbes, 2019) and Women's Leader Development Programs (WLDPs), specifically, are a growing niche area with the purpose of increasing an organization's collective capacity to effectively engage in leadership roles and processes (Day, 2000). Organizations and their leader development systems evolved to service men (Ely \& Padavic, 2007; Reichard et al., 2020), and as such, most extant research on leader development centers men (Vogel et al., 
2020). As a result, WLDPs are, at best, based on limited generalized research evidence and local program evaluation or, more often, the most recent fad (e.g., lean in), regardless of content rigor. Focusing on providing effective, evidenced-based WLDPs would significantly help organizations achieve gender parity in leadership. Rather than continuing to add to the crowded field of programs, we focus on consolidation and taking an evidenced-based approach to understanding and targeting what works best in WLDPs.

Although previous studies have provided a qualitative comparison of the content of general leader development programs to WLDPs, there has not been a qualitative study comparing WLDPs to each other (Sugiyama et al., 2016). Thus, we conduct a qualitative review of top WLDPs across the U.S. to identify common themes. We integrate those themes with existing research in the leader development field and provide evidence-based recommendations for training explicitly utilized for women in leadership. Comparing the content of top WLDPs to the literature on leadership training, women's leadership, and women's leader development, we determine the utilization of best practices within WLDPs to further narrow the gender disparity in leadership positions.

Several research questions guide this study: What are the current trends in program practices and content of top WLDPs? What claims of effectiveness are supported by the format, content, and audiences targeted by WLDPs? How do WLDP practices compare to existing research on women's leadership and leader development? Specifically, we seek to understand the types of WLDPs offered and identify strengths and gaps to guide organizations in modifying and implementing future programs designed to develop women leaders. By furthering this inquiry, we can provide both researchers and practitioners seeking to reduce the gender gap in leadership with concrete suggestions as to how to improve and develop effective WLDPs.

\section{METHODS}

To answer these research questions, we examined (1) the practices of top open enrollment WLDPs and (2) the academic literature on women's leadership and leader development. First, in our qualitative review of top open enrollment WLDPs, we identified common themes and provide an overview of the current training and practices explicitly utilized for women. We conducted a content analysis (Creswell, 2018) to quantify qualitative information by systematically sorting, summarizing, and comparing data while extracting major themes. We coded publicly available information from program descriptions, websites, and brochures to mirror program content available to inquiring leaders. Given that each WLDP's public information varies in presentation and content, it was essential to use a qualitative approach that allows for rich description, flexibility based on emergent findings, and data visualization that we sorted into themes. After coding the sample of WLDPs, we contrasted the emergent themes with extant literature on women's leadership and leader development identified through a literature search. In the results and discussion, we provide recommendations illuminating best, evidence-based practices for future WLDPs.

\section{Content Analysis}

WLDP Sample

To provide insight into the overlaps and gaps between the current curriculum of WLDPs and evidencebased practices suggested in the extant literature, our sample only included leader development programs specifically designed for women. We only examined 'open enrollment' WLDPs as these are available to any woman, available to find through a simple internet search, and information needed for coding was publicly available on program websites. Thus, WLDPs internal to a particular organization (e.g., Kaiser Permanente) were excluded from the sample. Finally, we only included WLDPs in the U.S. that use English as their primary instruction language. Based on these criteria, the final sample was drawn from the Financial Times' (2019) ranking of the top open-enrollment executive education programs. We identified a sample of 15 programs from institutions in the U.S. catering to women's leader development (see Table 1). As shown, 14 of the 15 open enrollment WLDPs identified were university-affiliated, with Cornell University providing two different WLDPs. 


\section{TABLE 1 \\ INSTITUTIONAL AFFILIATION OF THE TOP U.S.-BASED WOMEN'S LEADERSHIP DEVELOPMENT PROGRAMS, IN ALPHABETICAL ORDER}

\begin{tabular}{cl}
\hline$\#$ & Institutional Affiliation \\
\hline 1 & Center for Creative Leadership \\
2 & Columbia Business School \\
3 & Cornell University: S.C. Johnson College of Business (1) \\
4 & Cornell University: S.C. Johnson College of Business (2) \\
5 & Florida Atlantic University: College of Business \\
6 & Northwestern University: Kellogg School of Management \\
7 & Rutgers University \\
8 & Santa Clara University: Leavy School of Business \\
9 & Stanford Graduate School of Business \\
10 & University of California, Berkeley: Executive Education \\
11 & University of California, Los Angeles: Anderson School of Management \\
12 & University of Virginia: Darden \\
13 & Washington University: Olin Business School \\
14 & Wharton School of the University of Pennsylvania \\
15 & Yale University: School of Management \\
\hline
\end{tabular}

\section{Content Coding Protocol and Procedures}

Per protocol recommended by Creswell (2018), three doctoral students studying Psychology independently conducted open coding on an initial random sample of three programs. There was no a priori coding scheme before this first round of open coding. The three independent coders each created their unique coding categories according to the available public information of their assigned WLDP. Coders concluded this initial round of open coding by meeting to discuss common observations and themes and clarify any ambiguous or unique classifications. Next, the coders consulted with a leader development expert to finalize the coding scheme and ensure that it aligned with relevant concepts in the leadership development and women's leadership literature. We determined a final set of 30 coding categories through mutual agreement on common themes and expert feedback.

We segmented the final 30 categories into five major areas, each with its own set of unique codes: 1) basic information (e.g., cost), 2) training methods (e.g., assessment), 3) training focus (e.g., intrapersonal), 4) training topics (e.g., networking), and 5) program impact (e.g., organizational-level impact claims). See Table 2 for the complete list of coding categories and relevant results.

TABLE 2

CODING CATEGORIES AND RELEVANT RESULTS

\begin{tabular}{cll}
\hline Category & \multicolumn{1}{c}{ Specific Code } & \multicolumn{1}{c}{ Relevant Results } \\
\hline Basic & Cost & Range $\$ 3,000-\$ 26,000(\$ 8,000$ on average $)$ \\
Information & Duration & Range 6-65 hours $(30$ hours on average) \\
& Participants & $100 \%$ of WLDPs required at least 3 years of \\
& & leadership experience $(8$ on average) \\
& Training Setting & $60 \%$ of WLDPs are held in-person \\
& & $13 \%$ of WLDPs are held online \\
Training & & $27 \%$ of WLDPs are held in both settings \\
Methods & Assessment & $47 \%$ of WLDPs included some form of assessment \\
& & including $27 \%$ self-reflective, $13 \%$ network, and $7 \%$ \\
& & \\
\end{tabular}




\begin{tabular}{|c|c|c|}
\hline & Feedback & $\begin{array}{l}47 \% \text { of WLDPs included some form of feedback } \\
\text { including } 27 \% \text { from peers } 13 \% \text { from coaches, and } \\
7 \% \text { from } 360 \text { feedback }\end{array}$ \\
\hline & Information-Based Delivery & Included in $100 \%$ of WLDPs (e.g., panels, lectures) \\
\hline & Demonstration-Based Delivery & $33 \%$ of WLDPs utilized case studies \\
\hline & Practice- Based Delivery & $\begin{array}{l}33 \% \text { of WLDPs utilized simulations or experiential } \\
\text { exercises }\end{array}$ \\
\hline & Coaching & $\begin{array}{l}20 \% \text { of WLDPs utilized peer coaching } \\
40 \% \text { of WLDPs utilized professional coaching }\end{array}$ \\
\hline & Mentoring & $20 \%$ of WLDPs utilized peer mentoring \\
\hline & Pre-Work & Included in $27 \%$ of WLDPs (e.g., self-study) \\
\hline $\begin{array}{l}\text { Training } \\
\text { Focus }\end{array}$ & Intrapersonal & $\begin{array}{l}\text { Included in } 100 \% \text { of WLDPs (e.g., building } \\
\text { confidence) }\end{array}$ \\
\hline & Interpersonal & $\begin{array}{l}\text { Included in } 100 \% \text { of WLDPs (e.g., developing } \\
\text { networks) }\end{array}$ \\
\hline & Leadership & $\begin{array}{l}\text { Included in } 100 \% \text { of WLDPs (e.g., enhancing } \\
\text { leadership presence) }\end{array}$ \\
\hline & Business & $\begin{array}{l}\text { Included in } 100 \% \text { of WLDPs (e.g., strategic decision } \\
\text { making) }\end{array}$ \\
\hline & & $\begin{array}{l}0 \% \text { of WLDPs included transformational leadership } \\
\text { or LMX }\end{array}$ \\
\hline & Theoretical Concepts & $\begin{array}{l}20 \% \text { of WLDPs utilized at least one theoretical } \\
\text { concept (e.g., Implicit Leadership Theory, Goal } \\
\text { Setting Theory) }\end{array}$ \\
\hline Training & Networking & Included in $100 \%$ of WLDPs \\
\hline Topics & Mentoring & Included in $100 \%$ of WLDPs \\
\hline & Everyday Negotiations & Included in $80 \%$ of WLDPs \\
\hline & Conflict Management & Included in $53 \%$ of WLDPs \\
\hline & Decision-Making & Included in $53 \%$ of WLDPs \\
\hline & Confidence-Building & Included in $47 \%$ of WLDPs \\
\hline & Power Dynamics & Included in $33 \%$ of WLDPs \\
\hline & Career Transitions & Included in $33 \%$ of WLDPs \\
\hline & Forms of Bias & $\begin{array}{l}\text { Included in } 27 \% \text { of WLDPs (e.g., unconscious bias, } \\
\text { gender bias at work) } \\
0 \% \text { of WLDPs included Second-Generation Gender } \\
\text { Bias }\end{array}$ \\
\hline & Leading Change & Included in $27 \%$ of WLDPs \\
\hline $\begin{array}{l}\text { Program } \\
\text { Impact }\end{array}$ & Individual & $\begin{array}{l}100 \% \text { of WLDPs included individual level impact } \\
\text { claims (e.g., personal insight, skill development) }\end{array}$ \\
\hline & Organizational & $\begin{array}{l}73 \% \text { of WLDPs included organizational level impact } \\
\text { claims (e.g., ROI, increased retention rates) }\end{array}$ \\
\hline & Program Evaluation & $100 \%$ WLDPs solely evaluated participant reactions \\
\hline
\end{tabular}

Using this framework of five major categories and 30 themes, the three coders independently coded randomly assigned WLDPs until all 15 were complete. Overall, the coding process was straightforward, but in the rare instances that a coder had questions or if information was missing, the first author acted as a second coder and independently examined the WLDP content to finalize the code. 


\section{Literature Review}

We identified relevant literature on women's leadership and leader development in two primary ways. First, we conducted a search of PsycInfo and Web of Science using combinations of keywords of "gender," or "sex," or "women," and "lead*" or "development," or "training." We prioritized our review of abstracts based on the most-cited publications and publications in top organizational psychology and women's studies journals. Second, we examined the reference list of dominant review papers on women's leadership (e.g., Koenig et al., 2011; Paustian-Underdahl et al., 2014) and leader development (e.g., Lacerenza et al., 2017; Vogel et al., 2020) to identify additional relevant publications. Through reading the literature, we identified areas of overlap with WLDP practices as well as gaps where research evidence supported practices missing from top WLDPs.

\section{RESULTS}

We provide seven evidence-based recommendations to improve current and future WLDPs (see Table 3). Our recommendations are based on both the findings of our content analysis and existing literature on women's leadership and leader development. By comparing these two data sources, we elucidate and build upon current WLDPs' strengths as well as point out areas where existing gaps can be reduced.

TABLE 3

\section{EVIDENCE-BASED RECOMMENDATIONS FOR WLDPS}

\begin{tabular}{ll}
\hline$\#$ & Recommendation \\
\hline 1 & Identify Measurable Program Objectives Based on Needs Assessment \\
2 & Increase Access for Emerging, Developmentally Ready Leaders \\
3 & Cultivate a Paradox Mindset Around Leader and Gender Identity \\
4 & Leverage Experiential Learning and Feedback \\
5 & Expand Networks to Include Powerful Women and Men \\
6 & Educate Organizational Members About Second-Generation Gender Bias \\
7 & Align Evaluation with Program Objectives \\
\hline
\end{tabular}

\section{Identify Measurable Program Objectives Based on Needs Assessment}

Effective leader development programs begin with the end in mind by identifying measurable program objectives based on participants' needs (Lacerenza et al., 2017). All 15 of the WLDPs we investigated included a statement of key benefits, program outcomes, or impact; however, none reported basing those on an assessment of participants' needs. Further, we found such statements of program objectives to be vague and difficult to operationalize. For example, one program reported an objective of strengthening women's leadership skills, whereas another program asserted the outcome to lead one's firm to better enterprise-wide gender diversity. These vague program objectives beg the questions: What specific leadership skills are the program participants most in need of developing? At what threshold can we assess success for 'better' enterprise-wide gender diversity? Thus, we recommend that WLDPs identify effective program objectives based on an assessment of the participants needs.

Effective program objectives have three components: performance, condition, and criteria (Noe, 2019). An example of a program objective including all three components is as follows: During weekly team meetings, inspire member commitment by telling stories about the organization's history. Breaking this down, performance refers to the specific behavior that the program participant is expected to implement because of the training. So, instead of generic leadership skills, the specific behavior to be performed is telling stories about the organization's history. The condition refers to the context within or the tools required to enact that behavior (i.e., team meetings). Finally, the criteria establish the level of performance that is acceptable, such as quantity or quality. In this case, 'weekly' and 'inspire member commitment' are the criteria against which success can be evaluated. Having effective program objectives set participants' expectations and provide them with a sense of direction. They also direct the program design allowing the 
trainer to focus on 'need to know' desired outcomes. Objectives can be used to measure success and to facilitate future sales through marketing their results.

It may not be surprising that the WLDP objectives we observed were less than effective because none of the programs specified that they completed a needs assessment, which is how effective program objectives are generated. Needs assessment can occur at the organizational or individual level (Noe, 2019). Organizational needs assessment helps program designers understand the larger context within which the woman is leading (e.g., alignment with organizational strategy and competency models, available resources and support), and individual level needs assessment uncovers who needs training and in what specific areas. In externally run, open enrollment WLDPs where women from a variety of organizations are participating, organizational level needs assessment may not be feasible. However, individual level needs assessment is critical to move away from a generic program toward a WLDP tailored to participating women's unique needs.

Consider the example of two women completing the same WLDP. One woman develops by leaps and bounds, and the other does not develop or may even regress. This may be due to the lack of alignment of the program objectives and content with the second woman's developmental needs. By identifying the gap between current and desired leadership knowledge, skills, and performance, the program objectives and content can be tailored to target and shrink those gaps. For example, one approach of identifying individual needs is to conduct a pre-program 360-degree assessment and align the WLDP to target the leadership competencies in most need of development.

A generic WLDP creates a one-size-fits-all approach that not only neglects at least some participants' needs but also limits overall program impact. In a meta-analytic study on the effectiveness of 335 leadership training programs, Lacerenza and her colleagues (2017) found that leadership training based on a needs assessment had nearly twice the effect on what participants learned from the training and eight times the effect on their behavior back on the job. Given this, we recommend that all WLDPs shift toward the use of needs assessment to inform program objectives. One way this can be implemented is through the selection process, which we discuss next.

\section{Increase Access for Emerging, Developmentally Ready Leaders}

In addition to a possible mismatch between participant needs and program objectives and content, the particular women who are selected may not be optimal for maximizing gains from the WLDP. Most of the WLDPs we examined included some type of application form, typically including questions related to years of leadership and/or work experience and program expectations. However, in some cases this application was immediately followed by a payment request. Ostensibly, the selection requirements include one's ability to pay and a minimum number of years of experience. These are not the optimal selection criteria to ensure the effectiveness of WLDPs and narrow the gender gap in leadership.

Instead, WLDPs should increase access to emerging leaders by reducing cost and considering developmental readiness rather than experience. First, by lowering the cost of attendance, we can increase access and reduce a potent barrier to entry. The 15 WLDPs we analyzed cost participants, or their organizations, between $\$ 3,000$ and $\$ 26,000$. In addition to program entry costs, the cost of time away from work in terms of loss of productivity and revenue to the organization is significantly more for higher-level compared to emerging-level women leaders, further lowering the return on investment for their organization (Avolio et al., 2010). For this reason, attendees of these WLDPs require a great deal of either personal or organizational funding. Women in organizations with a large training budget can take advantage of formal programs, but aspiring women leaders in other organizations and institutions are not so privileged and may be left behind. Industries such as non-profit and academia, and individuals seeking to participate on their own, may be excluded from the top WLDPs simply due to budgetary constraints. Therefore, we believe there is room for improvement in the reach of current WLDPs, and our specific recommendation is to develop and promote alternative funding options to reach women in underrepresented and underfunded industries.

Developing emerging leaders provides a sustainable path to narrow the gender gap in leadership at all levels. In fact, leadership training programs are most effective among low-level leaders (Lacerenza et al., 
2017). We determined that all 15 top ranked WLDPs on the Financial Times' (2019) list target participants with at least three years of leadership experience. Although training existing leaders to be more effective is crucial, it's not enough to shrink the gender disparity in leadership as leadership develops over the lifespan (Murphy \& Johnson, 2011). Although women surpass men in terms of education around the globe (Global Gender Gap Report, 2020), the pipeline of women in leadership roles quickly falls off. By targeting emerging leaders, organizations can develop a strong bench of qualified women ready to take on higher leadership roles. Among emerging leaders, then, which women should be selected for WLDPs?

We recommend that emerging women leaders are selected based on their developmental readiness rather than experience. Leader developmental readiness reflects one's motivation, ability, and support for development (Reichard \& Beck, 2017) and is a predictor of success in leader development (Avolio \& Hannah, 2008, 2009). Women high in motivation to develop approach programs as an opportunity to learn and master content rather than prove their effectiveness. They believe that leaders can be made (versus born) and, thus, have confidence in their ability to improve as a leader (Avolio, 2005). Women high in the ability to develop are better at learning and they have stronger meta-cognitive skills that allow them to make sense out of challenging leadership experiences (Reichard \& Beck, 2017). Finally, women with support for development have supervisors, mentors, and organizations who are aware of and committed to their growth (Murphy et al., 2017). This trifecta of motivation, ability, and support results in selected women benefitting more from WLDPs than limiting access to those with funds and prior experience. Thus, organizations would be wise to select women leaders high in developmental readiness for WLDPs for greater returns on investment in their development, compared to leaders who are lacking in developmental readiness.

\section{Cultivate a Paradox Mindset Around Leader and Gender Identity}

Social interactions, ideologies, and culture teach us what it means to be a woman and what it means to be a leader (Reichard et al., 2020). Stereotypically feminine traits include being communal, friendly, and selfless, whereas leadership qualities align with more stereotypically masculine traits such as being assertive, decisive, and independent (Powell et al., 2002). What is normatively acceptable for the female gender role based on those cultural stereotypes makes its way into organizations (Gutek \& Morasch, 1982) forming an "implicit, background identity" at work (Ridgeway, 1997, p. 231) and creates both external and internal challenges for those striving to identify with and satisfy both the female gender role and the leader role norms (Ely et al., 2011). Those stereotypically feminine qualities are often seen at odds with the qualities of a successful leader, and women are often judged as lacking those masculine qualities deemed necessary to be an effective leader (Fletcher, 2004). Furthermore, as outlined in role congruity theory, prejudice is directed toward women leaders due to the misalignment between feminine characteristics attributed to women as a group versus the masculine nature of the leadership role stereotype (Eagly \& Karau, 2002). Based on traditional conceptualizations of leadership as command and control, women face a double bind when holding true to both their feminine gender role and a leadership role (Eagly \& Karau, 2002). The double bind can be internalized by women leaders, and may result in a dilemma mindset, where women feel they need to choose to embody one set of role norms or the other (Zheng et al., 2018). This can result in a major barrier for women leaders in integrating these two identities into their broader self-views.

Thus, our next recommendation relates to facilitating the simultaneous presence of both a strong leader identity and a female gender identity, which helps women leaders achieve relational authenticity (Eagly, 2005). More specifically, our recommendation is to cultivate a paradox mindset (Zheng et al., 2018). By endorsing a paradox mindset, aspiring women leaders view it as possible to simultaneously hold and enact both their leader and gender identity (Zheng et al., 2018). In other words, both identities can coexist in their self-concepts.

Therefore, we investigated how WLDPs are influencing women's implicit leadership theories and helping women to develop their own leader identities (Day \& Dragoni, 2015). A primary goal of WLDPs is to address and support women through these specific identity barriers (Debebe, 2011; Ely et al., 2011) surrounding the contrast of implicit leader and gender identities (Eagly \& Karau, 2002). We provide two strategies to aid WLDPs in strengthening and integrating their leader identity and their feminine gender identity: (1) encourage women to anchor their leadership in their unique values, passion, and purpose (i.e., 
why a woman leads), and (2) expand the conceptualization of effective leadership to align with the feminine gender role (i.e., how a woman leads).

First, to achieve authenticity, leaders must know and act upon their values, passions, and purpose (Avolio et al., 2004). All 15 of the WLDPs we reviewed for the present study included some type of values assessment or meaning-making exercise that could help facilitate the connection to personal purpose. Future WLDPs should emphasize the importance of anchoring a leadership position in personal values, passion, and purpose. This means making the why a woman leads clear to herself and her followers. Passion and purpose refer to the motivation or underlying cause driving one's leadership efforts (Bronk \& McLean, 2016) and rests on the aspiring leader's values and aspirations for the future. Anchoring leadership roles in purpose enables women to redirect their attention toward shared goals and what they need to learn to achieve those goals (Ibarra et al., 2013). To the extent a female leader's passion and purpose is clear to both herself and her followers, she can lead more authentically (Avolio, 2011). This allows women to both align their sense of self and more significant meaning in life with their leadership position and reduce role incongruencies they might feel, or that others may penalize them for (Zheng et al., 2018).

Not only does the why a woman lead help address any internalized incongruence between leader and feminine gender roles, but how a woman leads is also critical. Thus, we recommend that WLDPs expand the conceptualization of effective leadership to align more closely with the feminine gender role. Leader behaviors that most align with, or at least do not contradict, feminine gender role norms are those that are more interpersonal in nature, democratic, and transformational (Eagly \& Johannesen-Schmidt, 2001).

Because it is considered both an effective and feminine leadership style (Eagly et al., 2003), WLDPs should incorporate training around the concepts and behaviors of transformational leadership (Avolio, 2011; Sosik \& Jung, 2018). Regarding its effectiveness, transformational leaders move followers beyond their self-interests for the good of the group, organization, or society (Bass, 1987) yielding performance beyond expectations (Bass, 1985). Multiple meta-analyses have found that transformational leadership has positive associations with leader effectiveness, follower satisfaction (Dumdum et al., 2013; Lowe et al., 1996), follower motivation (Judge \& Piccolo, 2004), follower task and contextual performance, team performance, and organizational performance (Wang et al., 2011). Not only has transformational leadership been repeatedly identified as one of the most effective leadership styles (Sosik \& Jung, 2018), but in their meta-analysis Eagly et al. (2003) found that women are more transformational leaders than men. This finding may reflect the alignment between the feminine gender role norms and the four transformational leadership behaviors.

Referred to as the 4 Is, the transformational leadership style consists of four key behaviors - idealized influence, inspirational motivation, intellectual stimulation, and individualized consideration. Whereas traditional views of leadership as command and control conflict with the stereotypical feminine gender role, creating a 'think manager-think male' phenomenon (Schein \& Davidson, 1993), instilling pride and talking about values and beliefs (idealized influence), articulating and talking enthusiastically about a compelling future vision (inspirational motivation), re-examining critical assumptions and suggesting new work strategies (intellectual stimulation), and treating others as individuals and spending time teaching and coaching followers (individualized consideration; Bass \& Riggio, 2006) arguably align with or at least do not contradict the feminine gender role and the associated identity that women leaders possess (Eagly \& Johannesen-Schmidt, 2001). Thus, by training women leaders on transformational concepts, their conceptualization of leadership shifts to be inclusive of behaviors consistent with the female gender role. This shift enables the paradox mindset. It is possible to be both an effective leader and a norm-conforming woman, should she so choose. This can help to dismantle the internalized discrepancy that may face some women leaders and ease their identity integration. Despite the effectiveness of transformational leadership behaviors and their compatibility with feminine gender role expectations, none of the WLDPs we examined included transformational leadership concepts.

Taken together, we recommend that WLDPs cultivate a paradox mindset around a woman's leader and gender identity by encouraging participants to lead from their core values and passions and by expanding women's conceptualization of effective leadership to include transformational leadership, which better aligns with the cultural stereotypes associated with their gender role. 


\section{Leverage Experiential Learning and Feedback}

Our fourth recommendation is that WLDPs leverage experiential learning and feedback. Like the Chinese proverb, read ten thousand books, walk ten thousand miles, aspiring leaders must not only study leadership, but they must practice leadership. Whereas training occurs over a short time frame with targeted activities designed to teach a skill or remediate a performance gap in employees' current jobs (e.g., emotional and social skills training), development occurs over a longer time frame and emphasizes preparing employees for future assignments or enabling long-term organizational goals (Noe, 2019). Leader development occurs over one's lifespan (Murphy \& Johnson, 2011) and is largely a result of experiential learning (McCall, 2010) and deliberate practice (Day, 2010). Certain experiences matter more than others because of the powerful challenges they present (McCall, 2010). Experiences that are unexpected, complex, novel, and with high stakes drive leaders to slow down, question normal operating procedures, pay attention to outcomes, and ultimately develop their leadership (Reichard et al., 2015). Challenging assignments may include an increase in supervisory scope, creating change (e.g., a new initiative), rotating or transitioning jobs (e.g., line to staff), engaging diverse stakeholders, or working in different cultures (Wilson \& Yip, 2010). Although it is out of the scope of external WLDPs to determine what leadership experiences women have in their organizations, there are a number of strategies that programs can implement by reconceptualizing away from short-term training and toward long-term leader development.

First, WLDPs can help women learn from their past leadership experiences. Development of leadership rests on the meaning leaders attach to past life experiences (Shamir \& Eilam, 2005). We create a personal narrative through our unique interpretation of our life events by answering the questions who was I, who am I (and why), how have I become a leader, why have I become a leader, and who might I become. WLDPs can help program participants craft a coherent connectedness among their life events to help them lead from a clear base of knowledge of their values and passions. For example, WLDPs could use a lifeline activity to help participants identify and chronologically map out significant life events or experiences that have impacted their values, purpose, and leadership development. This activity is a scaffolded process, as participants only reflect back on five to 10 -year increments at a time and end by identifying their values and personal qualities that relate back to their significant development experiences. Such sensemaking processes can boost women's ambition to seek powerful leader positions (Greenlee et al., 2014) and also facilitate identity integration (Hammond et al., 2017), supporting our third recommendation.

In addition to reflection on past leadership experiences, WLDPs should provide new experiences in the context of the program itself because practice-based, rather than information-based, leadership training methods are most effective (Lacerenza et al., 2017). To begin, key leadership behaviors should be identified (via needs assessment) and explained clearly to program participants (i.e., program objectives). Activities should be used that show women similar to program participants demonstrating both effective and ineffective key behaviors (Bandura, 1977). Then, coupled with support, the bulk of program time should be spent on providing challenging, realistic, and repeated practice sessions using increasingly difficult simulations accompanied with specific behavioral feedback (Van et al., 2010). Of the 15 WLDPs that we examined, only two publicly advertised including leadership simulations and just three incorporated experiential exercises. However, $47 \%$ of WLDPs did incorporate some form of feedback, whether that be from other peers in the program (27\%), from professional coaches (13\%), or from a 360 assessment (7\%).

The provision of repeated practice with behavioral feedback has implications for the timeframe of WLDPs. Of the WLDPs that we reviewed, program duration ranged from as few as six hours within a single day or up to 65 hours of programming spanning several months and, in one case, an entire year. Although Lacerenza et al. (2017) found no differences in learning outcomes depending on the length of leadership training, they did find that longer programs had a larger effect on transfer of leadership behaviors back to the workplace and for team and organizational results. Across the board, the Lacerenza et al.'s (2017) metaanalysis indicated that the most effective programs spaced out program content across time. Thus, we recommend that WLDPs can better leverage experiential learning and feedback by creating multiple sessions, spaced over a period of time, to create a practice of reflection and learning.

At some point, however, the WLDPs must end. In addition to making meaning from past experiences and creating opportunities for practice and feedback within the program itself, WLDPs can help women 
identify and seek out future experiences needed to develop their competence based on personal areas of growth. Assessment feedback (e.g., self or 360) not only facilitates leader development (Lacerenza et al., 2017), but it also helps participants identify their leadership strengths to build upon in the future and their leadership weaknesses to improve. WLDPs can not only help facilitate this self-knowledge by providing assessment feedback, but they can also assist women with the following: identifying what future leadership experiences they need to become a more effective leader, establishing strategies to work around any foreseen obstacles to their development, and leveraging resources, including social support, to pursue and learn from those new experiences. By supporting targeted, deliberate practice in individualized areas of growth (Day, 2010), WLDPs can ensure that aspiring women leaders are pursuing a positive trajectory of mindful engagement over their lifespan (DeRue \& Ashford, 2010).

\section{Expand Networks to Include Powerful Women and Men}

Social support is a critical factor underlying the effectiveness of women's leader development, reflected by the fact that $100 \%$ of the WLDPs we examined included some type of networking component. However, having a single individual supporting a woman's development is not adequate. Experts indicate that developing leaders benefit most by having a diverse developmental network (Higgins \& Kram, 2001). Having a supportive supervisor, leadership coach, step-ahead and peer mentors, and sponsors are particularly essential as a female employee integrates the identity of 'leader' into their self-concept (Ibarra, 2003; Yip et al., 2020). A recommendation we have for current WLDPs is to include both powerful women and men in the program's networking component.

Simply bringing women together from within or across organizations in the context of a WLDP provides invaluable and often unmeasured benefits in terms of expanding networks of connections. Having a safe space to share leadership challenges and learn and grow as leaders together can create strong bonds among participating women leaders. Women leaders also need to have access to a developmental network of other women leaders to act as role models in the social context and facilitate sense-making (Petriglieri \& Petriglieri, 2010). Visible women leaders can serve as influential role models that contribute to other women's leader efficacy (Olsson \& Martiny, 2018) and effectiveness (Latu et al., 2019). Connecting with other women leaders not only provides necessary role modeling, but also potential career opportunities because high-level women leaders are 'Regal Leaders' not 'Queen Bees,' as they are more likely than men to hire and promote other women (Arvate et al., 2018).

Given these benefits, the common WLDP practice of facilitating networking relationships among women should continue, but it is not enough. Powerful men need to be intentionally included in WLDPs to expand and diversify women's developmental networks. Women's typical networks do not provide the same career advancement opportunities as men's. In fact, research conducted on both men's and women's professional social networks has shown that they are inherently different (Szell \& Thurner, 2013). Men typically have network ties that provide them with both formal and informal mentors and are more likely to result in promotions (Ibarra et al., 2010). In contrast, women's networks usually result in fewer leadership opportunities, provide less visibility, and generate less recognition and endorsement (Ibarra, 1993). Although there is great value in providing women the social and professional support of other women, for career advancement, women need to have access to the pre-existing male networks that dominate the upper echelons of leadership.

\section{Educate All Organizational Members About Second-Generation Gender Bias}

Although there are many systemic underlying causes (Badura et al., 2018; Reichard et al., 2020), some researchers attribute a portion of the existing gender gap to second-generation gender bias. Ely et al. (2011, p. 475) defined second-generation gender bias as “the powerful and often invisible barriers to women's advancement that arise from cultural beliefs about gender, as well as workplace structures, practices, and patterns of interaction that inadvertently favor men." Second-generation gender bias is more insidious and intangible than other forms of bias, making it difficult to identify, address, and dismantle. Often secondgeneration gender bias arises in a beneficent manner and is viewed as supportive or protective. But in 
actuality, its effect impedes women's ability to succeed in leadership roles by preventing them from gaining the necessary experiences to see themselves as leaders or be seen as leaders (DeRue \& Ashford, 2010).

WLDPs can explicitly address this by educating participants on second-generation gender bias (Ely et al., 2011), which we did not find evidence of in any of the 15 programs included in our review. Because second-generation gender bias often occurs without intent, individuals and organizations possessing this bias create an environment in which women are disadvantaged and fail to reach their full potential. Without identifying and understanding second-generation gender bias, individuals may attribute the discrepancies in achievement between men and women to stereotypes, often negative, about women. When women can recognize the effects of second-generation gender bias, it empowers them to work against the pushback they receive (Ibarra et al., 2013).

Whereas organizations may address more overt discrimination through official policy and procedures, they may fail to reach their full, inclusive potential by not recognizing or addressing more subtle forms of gender bias. We assert that educating all organizational members, including men, on second-generation gender bias will be the most beneficial path forward for women in leadership for three reasons. First, if only women are educated about second-generation gender bias, they are then solely tasked with having to identify and take action toward gender-based discrimination at work. This would only require more of their time and energy, beyond facing the discrimination in the first place, which could have been allocated elsewhere, such as developing their leadership. Second, women are underrepresented in positions of power (Catalyst, 2020), so by involving other organizational members in this initiative, organizations are more likely to target employees who have the power and ability to take action and make systematic changes. And lastly, we cannot neglect the pervasiveness and power of organizational culture. An organization's culture involves all members of the organization and stems from members' shared history and assumptions about reality (Schein, 1990). Organizational culture also creates an environment that defines the parameters in which a leader operates (Luthans et al., 1998). Therefore, an organizational culture, and by extension an organization, that is free from the impact of second-generation gender bias would not be possible unless education is offered to a majority, if not all, of its members.

\section{Align Evaluation With Program Objectives}

Our final recommendation for improving WLDPs is to align the program evaluation with its objectives. The dominant training evaluation outcome framework includes the four levels of reactions, learning, transfer of behavior, and results (Kirkpatrick, 1959).

\section{Participant Reactions}

Participant reactions or attitudes (e.g., training value, utility, and satisfaction) about the program are the most widely collected data in organizational training evaluation (Patel, 2010), and all 15 of the WLDPs we analyzed measured participant reactions to the program. However, reactions were the sole evaluation outcome considered by WLDPs. Only gathering participant reactions severely limits the understanding of program effectiveness and inhibits future program improvements. Although positive reaction outcomes can be necessary precursors for more downstream outcomes (e.g., transfer of training to their leadership practice, motivation to learn; Blume et al., 2009), alone they are insufficient to determine the WLDP effectiveness and should not be used as a proxy (Hughes et al., 2016). Our final recommendation for WLDPs is to broaden and align evaluation efforts to examine the intended program objectives more comprehensively.

Assuming that our previous recommendation to identify measurable program objectives based on needs assessment is followed, WLDPs can create a through-line from participant needs to program objectives to program content to program evaluation. By aligning evaluation strategies with need-based program objectives, evaluators can explicitly determine to what extent intended objectives are being met. Depending on the program objectives, this may mean adding learning, transfer, and results outcomes to the evaluation (Arthur et al., 2003). 


\section{Learning}

Learning represents the change that occurs in knowledge, behaviors, or skills as a result of the training. Meta-analytic evidence supports the positive effect that leadership training programs have on learning outcomes (Lacerenza et al., 2017; Powell \& Yalcin, 2010). While this recommendation should be applied to all genders and organizational members, specifically for the focus of this article, WLDPs, we can claim that the current scope of learning outcomes needs be expanded to include identifying and overcoming implicit biases so that participants understand how more constructive thought patterns might benefit them in identifying and overcoming leadership challenges. Currently, programs that seek to identify biases and challenge assumptions have the greatest effect on enhancing participant learning (Lacerenza et al., 2017).

\section{Transfer}

Transfer or behavior outcomes refer to the extent to which trainees engage in utilizing the skills and abilities learned during the training to their job, and how training affects job performance (Alliger et al., 1997; Kirkpatrick, 1959). Because the goal of leadership training is to develop trainees' abilities to engage effectively in leadership roles and processes, transfer outcomes are critical for determining the effectiveness of leadership training programs. However, transfer measures are currently contingent upon a number of other factors and results in what some have identified as a "transfer problem" (Baldwin \& Ford, 1988). Although meta-analytic research provides evidence that leadership training programs result in the transfer of learning concepts (Lacerenza et al., 2017), this is an area that deserves further exploration for WLDPs.

\section{Results}

Results refer to a training program's effect on achieving organizational outcomes (Kirkpatrick, 1959). Traditionally, results are measured with various return on investment indicators such as profits, turnover, and absenteeism. For leadership training, specifically, prior research indicates that return on development investment ranges from a low negative return to over $200 \%$ depending on different factors (e.g., length of the intervention, level of manager participating; Avolio et al., 2010). For WLDPs, evaluators should include additional results metrics such as compensation, promotion, retention, and advancement of women in comparison to their male counterparts, especially in light of the fact that $73 \%$ of WLDPs claimed at least one organizational benefit as a result of women attending their program - yet no programs publicly advertised measuring results metrics. In fact, we posit that these additional results metrics should be the ultimate aim of WLDPs, and evaluation process should be reconfigured to represent that focus.

\section{Formative Evaluation}

Finally, beyond measuring WLDP outcomes of reactions, learning, transfer, and results (i.e., summative evaluation), efforts should also include elements of formative evaluation. Formative evaluation refers to systematically gathering feedback during the development or critical period of a program and utilizing that feedback to make ongoing improvements to the program curriculum (Weiss, 1997). Instead of rendering effectiveness judgment on a program after the fact, formative evaluation seeks to develop the program, ensure implementation fidelity, and assess participant engagement throughout (Weiss, 1997). It is important for WLDPs to include formative evaluations because the relationship between gender and leadership is an evolving concept. Programs must prioritize continuous feedback that is both informed by advances in literature as well as by the needs of their participants, to ensure that they are most effectively meeting the needs of women leaders in the current and ever-changing global context.

\section{DISCUSSION}

The gender gap in leadership is not new and without a concerted, systematic effort, it will not go away any time soon. Over the past 50 years, 85 countries including the U.S. have had a man as head of state, and in the private sector, $64 \%$ of managers are men (Global Gender Gap Report, 2020). Unfortunately, since the onset of the COVID-19 pandemic, women have faced disproportionate disadvantage in terms of job loss, career stalling, and financial security (Madgavkar et al., 2020). The pandemic has only intensified 
challenges that women already faced (e.g., the second shift; Hochschild, 1989) and upended resources to ease the burden of working women (e.g., school closures and childcare; Florant et al., 2020). Even though 40 countries have achieved gender parity and have shown that an accelerated pace is possible, at the current rate of change, it will take nearly 100 years to achieve gender parity across 105 countries (Global Gender Gap Report, 2020).

Developing women leaders is but one of a system of integrated organizational changes necessary to narrow the gender gap in leadership. Working in concert with the adoption of wide-spread policies and procedures targeted to prevent and prohibit gender discrimination (Ely et al., 2011), we recommend seven actions born out of existing practices and available evidence for developing women leaders that can make a significant difference in women's representation and effectiveness in leadership positions. The current open-enrollment WLDPs ranked highest in the United States by Financial Times (2019) incorporate important concepts integral to developing women leaders, and we have identified several areas for programs to expand upon to decrease the gender disparity in leadership positions.

Although extant WLDPs identify broad outcomes, they can be improved by identifying measurable program objectives based on an assessment of individual needs of women accepted into their program. Along these lines, we recommend selecting emerging women leaders based on their readiness to develop as a leader (i.e., high levels of motivation, ability, and support to develop) rather than on prior experience. WLDPs should cultivate a paradox mindset around leader and gender identity by focusing on helping women uncover their values, passion, and purpose for leading and by training women in effective and gender-neutral transformational leadership behaviors. Acknowledging that most growth happens outside of a formal training, WLDPs can leverage experiential learning and feedback by helping women learn from their past leadership experiences through sensemaking and provide them new experiences in the context of the WLDP such as leadership simulations accompanied by behavioral feedback.

Networking and mentoring were prevalent themes across the WLDPs we reviewed. WLDPs can build upon this strength by expanding women's developmental networks to include both powerful women and men. Women in power do help other women progress (Arvate et al., 2018), but aspiring women's networks that do not include powerful men are missing a significant opportunity to optimize developmental experiences and get needed support and sponsorship. Men should not only be included in women's developmental networks but should also be educated as champions to help address subtle forms of discrimination known as second-generation gender bias. By educating all organizational members on this phenomenon, WLDPs can facilitate awareness and systems-level change needed to truly advance women. Finally, WLDPs should align program evaluation with identified program objectives. Butts in seats (i.e., number of women participating) is all too often used as an indicator of program success, but (pun intended) participation is only the first step. Formative and summative evaluation can facilitate WLDP improvements to ensure that identified program objectives are being met and, ultimately, that progress is being made toward gender parity in leadership.

\section{Limitations and Future Research}

Our approach in this paper has both methodological and practical limitations. Methodologically, we started our inquiry into how top open-enrollment WLDPs in the U.S. can be improved upon to help further reduce the gender parity in leadership. Through WLDP content analysis, we coded top programs, uncovered a variety of themes, and identified recommendations based on publicly available program content, such as websites and program brochures. Although this analysis has yielded valuable insights, a deeper look at the content of WLDPs would allow for a greater understanding of the current landscape. For example, it may have been the case that WLDPs did, in fact, conduct needs assessments and simply did not report that information publicly. We recommend that future researchers conduct interviews with program directors and facilitators to uncover more about the focus of the WLDPs and dive deeper into gender-related topics and how they unveil and address the complexities of being a woman in leadership.

Practically, focusing on WLDPs as the sole solution to gender parity is short-sighted. In fact, aspiring women leaders may greatly benefit from leadership development programs that allow mixed-sex enrollment. For example, one of the often-unintended leadership development program benefits is 
networking among high-potential program participants during coffee breaks, lunch discussions, or teambuilding activities. Building relationships among emerging, high-potential male and female leaders across the organization can reap dividends for years to come as they ascend the ranks to higher levels. However, our perspective aligns with that of Ely and her colleagues (2011) which is that leadership development should occur in a variety of settings and with a variety of audiences over the course of a leader's career. Supplementing traditional, mixed-gender leadership development programs with the benefits specific to WLDPs (e.g., providing a psychologically safe space for self-reflection and identity work, opportunity to discuss shared experiences, placing women in the majority position; Ely et al., 2011) provides leaders with novel opportunities to meet varying objectives. Although there are some weaknesses restricting leader development programs to only women, we believe that the benefits outweigh the drawbacks and that pursuing ways to improve WLDPs is a significant and worthwhile endeavor. Therefore, our purpose here was to provided evidence-based recommendations for improving WLDPs, one piece to the gender parity puzzle.

Similarly, developing individual women leaders while ignoring the structural organizational forces impeding women's progress is insufficient. In fact, focusing on 'fixing the women' (Ely et al., 2011) through WLDPs may be damaging to aspiring women's leadership ambitions as it sends the message that if they are just a more effective leader, then they will find success while organizational barriers persist. Aspiring women face a labyrinth of obstacles in their ascension to leadership (Eagly \& Carli, 2007) that leader development alone is inadequate to maneuver. Examples of organizational or socially derived barriers include gender role norms, stereotypes, and bias (Eagly \& Karau, 2002); risk of intense scrutiny (Diehl \& Dzubinski, 2016); lack of quality or quantity of mentors, sponsors, and networks (Ely \& Padavic, 2007); and domestic responsibilities (e.g., the second shift; Hochschild, 1989). Thus, focusing energy on solitary women, while beneficial, often rests a systemic solution on the backs of individuals. We must consider other initiatives, outside of WLDPs, to address structural obstacles facing women on the path to leadership (Reichard et al., 2020). Rules and procedures; selection, promotion, and termination; performance monitoring, evaluation, and appraisal; reward systems; authority and decision making; and positions, tasks, and status are all relevant organizational structures that must be reconsidered to drive women's leadership equity (Trainor, 2021).

\section{CONCLUSION}

At the current rate, gender parity will not occur for over 100 years (Global Gender Gap Report, 2020). Women's leader development is one of many important strategies that are needed to accelerate progress toward gender parity. We provide a description of the landscape of top open-enrollment WLDPs and contrast them with extant academic literature on women's leadership and leader development. We urge WLDP administrators to adopt our evidence-based recommendations, while simultaneously considering other initiatives to address structural obstacles. With a concerted, systematic effort, organizations can narrow the gender gap and advance women's leadership.

\section{ACKNOWLEDGEMENTS}

The authors wish to recognize the contributions and support provided by Cecelia Dotzler and Courtney Wylie in the early stages of this endeavor. 


\section{REFERENCES}

Alliger, G.M., Tannenbaum, S.I., Bennet, W., Jr., Traver, H., \& Shotland, A. (1997). A meta-analysis of the relations among training criteria. Personnel Psychology, 50(2), 341-358. https://doi.org/10.1111/j.1744-6570.1997.tb00911.x

Arthur, W., Jr., Tubre, T., Paul, D.S., \& Edens, P.S. (2003). Teaching Effectiveness: The relationship between reaction and learning evaluation criteria. Educational Psychology, 23(3), 275-285. https://doi.org/10.1080/0144341032000060110

Arvate, P.R., Galilea, G.W., \& Todescat, I. (2018). The queen bee: A myth? The effect of top-level female leadership on subordinate females. The Leadership Quarterly, 29(5), 533-548. https://doi.org/10.1016/j.leaqua.2018.03.002

Avolio, B.J. (2005). Leadership development in balance: Made/born. Lawrence Erlbaum Associates Publishers.

Avolio, B.J. (2011). Full range leadership development. Sage. https://doi.org/10.4135/9781483349107

Avolio, B.J., Avey, J.B., \& Quisenberry, D. (2010). Estimating return on leadership development investment. The Leadership Quarterly, 21(4), 633-644.

Avolio, B.J., Gardner, W.L., Walumbwa, F.O., Luthans, F., \& May, D.R. (2004). Unlocking the mask: A look at the process by which authentic leaders impact follower attitudes and behavior. The Leadership Quarterly, 15, 801-823. https://doi.org/10.1016/j.leaqua.2004.09.003

Avolio, B.J., \& Hannah, S.T. (2008). Developmental readiness: Accelerating leader development. Consulting Psychology Journal: Practice and Research, 60(4), 331-347. https://doi.org/10.1037/1065-9293.60.4.331

Avolio, B.J., \& Hannah, S.T. (2009). Leader developmental readiness. Industrial and Organizational Psychology: Perspectives on Science and Practice, 2(3), 284-287. https://doi.org/10.1111/j.17549434.2009.01150.x

Badura, K.L., Grijalva, E., Newman, D.A., Yan, T.T., \& Jeon, G. (2018). Gender and leadership emergence: A meta-analysis and explanatory model. Personnel Psychology, 71(3), 335-367. https://doi.org/10.111/peps.12266

Baldwin, T.T., \& Ford, K.J. (1988). Transfer of training: A review and directions for future research. Personnel Psychology, 41(1), 63-105. https://doi.org/10.1111/j.1744-6570.1988.tb00632.x

Bandura, A. (1977). Social Learning Theory. Prentice-Hall.

Bass, B.M. (1985). Leadership and Performance Beyond Expectations. Free Press.

Bass, B.M. (1987). Bass \& Stogdill's Handbook of Leadership: Theory, Research \& Managerial Applications. Free press.

Bass, B.M., \& Riggio, R.E. (2006). Transformational Leadership (2nd edition). Lawrence Erlbaum Associates Publishers. https://doi.org/10.4324/9781410617095

Blume, B.D., Ford, K., Baldwin, T.T., \& Huang, J.L. (2009). Transfer of training: A meta-analytic review. Journal of Management, 36(4), 1065-1105. https://doi.org/10.1177/0149206309352880

Bronk, K.C., \& McLean, D. (2016). The role of passion and purpose in leader developmental readiness. New Directions for Student Leadership, 149, 27-36. DOI: 10.1002/yd.20159

Catalyst. (2020). Women in Management. New York: Catalyst. Retrieved November 20, 2020, from https://www.catalyst.org/research/women-in-management/

Creswell, J.W. (2018) Qualitative Inquiry \& Research Design: Choosing Among Five Approaches (2nd edition). Sage.

Day, D.V. (2000). Leadership development: A review in context. The Leadership Quarterly, 11(4), 581613. https://doi.org/10.1016/S1048-9843(00)00061-8

Day, D.V. (2010). The difficulties of learning from experience and the need for deliberate practice. Industrial and Organizational Psychology: Perspectives on Science and Practice, 3(1), 41-44. https://doi.org/10.1111/j.1754-9434.2009.01195.x 
Day, D.V., \& Dragoni, L. (2015). Leadership development: An outcome-oriented review based on time and levels of analyses. Annual Review of Organizational Psychology and Organizational Behavior, 2, 133-156. https://doi.org/10.1146/annurev-orgpsych-032414-111328

Debebe, G. (2011). Creating a safe environment for women's leadership transformation. Journal of Management Education, 35(5), 679-712. doi:10.1177/1052562910397501

DeRue, D.S., \& Ashford, S.J. (2010). Who will lead and who will follow: A social process of leadership identity construction in organizations. Academy of Management Review, 35(4), 627-647. https://doi.org/10.5465/amr.35.4.zok627

Diehl, A.B., \& Dzubinski, L.M. (2016). Making the invisible visible: A cross-sector analysis of genderbased leadership barriers. Human Resource Development Quarterly, 27, 181-206.

Dumdum, U.R., Lowe, K.B., \& Avolio, B.J. (2013). A Meta-Analysis of Transformational and Transactional Leadership Correlates of Effectiveness and Satisfaction: An Update and Extension. Transformational and Charismatic Leadership: The Road Ahead 10th Anniversary Edition, 5, 39-70. https://doi.org/10.1108/s1479-357120130000005008

Eagly, A.H. (2005). Achieving relational authenticity in leadership: Does gender matter? The Leadership Quarterly, 16, 459-474. https://doi.org/10.1016/j.leaqua.2005.03.007

Eagly, A.H., \& Carli, L.L. (2007). Through the Labyrinth: The truth about how women become leaders. Harvard Business School Press: Boston, MA.

Eagly, A.H., \& Johannesen-Schmidt, M.C. (2001). The leadership styles of women and men. Journal of Social Issues, 57(4), 781-797. https://doi.org/10.1111/0022-4537.00241

Eagly, A.H., Johannesen-Schmidt, M.C., \& van Engen, M.L. (2003). Transformational, transactional, and laissez-faire leadership styles: A meta-analysis comparing women and men. Psychological Bulletin, 129(4), 569-559. https://doi.org/10.1037/0033-2909.129.4.569

Eagly, A.H., \& Karau, S.J. (2002). Role congruity theory of prejudice toward female leaders. Psychological Review, 109(3), 573-598. https://doi.org/10.1037/0033-295X.109.3.573

Ely, R.J., Ibarra, H., \& Kolb, D.M. (2011). Taking gender into account: Theory and design for WLDPs. Academy of Management Learning and Education, 10(3), 474-493. https://doi.org/10.5465/amle.2010.0046

Ely, R., \& Padavic, I. (2007). A feminist analysis of organizational research on sex differences. The Academy of Management Review, 32(4), 1121-1143. https://doi.org/10.5465/amr.2007.26585842

Financial Times. (2019). Business Education. U.K.: Financial Times. Retrieved September 20, 2019, from http://rankings.ft.com/businessschoolrankings/executive-education-open-2019

Fletcher, J.K. (2004). The paradox of post heroic leadership: An essay on gender, power, and transformational change. The Leadership Quarterly, 15(5), 647-661. https://doi.org/10.1016/j.leaqua.2004.07.004

Florant, A., Noel, N., Stewart, S., \& Wright, J. (2020). COVID-19: Investing in black lives and livelihoods. McKinsey \& Company.

Forbes. (2019). Leadership Development Is A \$366 Billion Industry: Here’s Why Most Programs Don't Work. New York: Forbes. Retrieved September 20, 2019, from https://www.forbes.com/sites/chriswestfall/2019/06/20/leadership-development-why-mostprograms-dont-work/?sh=10ee4bc861de

Global Gender Gap Report. (2020). World Economic Forum 2019. Retrieved March 22, 2021, from https://www.weforum.org/reports/gender-gap-2020-report-100-years-pay-equality

Greenlee, J., Holman, M.R., \& VanSickle-Ward, R. (2014). Making it personal: Assessing the impact of in-class exercises on closing the gender gap in political ambition. Journal of Political Science Education, 10(1), 48-61. https://doi.org/10.1080/15512169.2013.859083

Gutek, B.A., \& Morasch, B. (1982). Sex-ratios, sex-role spillover, and sexual harassment of women at work. Journal of Social Issues, 38(4), 55-74. https://doi.org/10.1111/j.1540-4560.1982.tb01910.x

Hammond, M., Clapp-Smith, R., \& Palanski, M. (2017). Beyond (just) the workplace: A theory of leader development across multiple domains. Academy of Management Review, 42(3), 481-498. https://doi.org/10.5465/amr.2014.0431 
Higgins, M.C., \& Kram, K.E. (2001). Reconceptualizing mentoring at work: A developmental network perspective. Academy of Management Review, 26(2), 264-288. https://doi.org/10.5465/amr.2001.4378023

Hochschild, A. (1989). The second shift: Working parents and the revolution at home. New York, NY: Viking.

Hughes, A.M., Gregory, M.E., Joseph, D.L., Sonesh, S.C., Marlow, S.L., Lacerenza, C.N., . . Salas, E. (2016). Saving lives: A meta-analysis of team training in healthcare. Journal of Applied Psychology, 101(9), 1266-1304. https://doi.org/10.1037/ap10000120

Ibarra, H. (1993). Personal networks of women and minorities in management: A conceptual framework. Academy of Management Review, 18(1), 56-87. https://doi.org/10.5465/amr.1993.3997507

Ibarra, H. (2003). Working Identity: Unconventional Strategies for Reinventing Your Career. Harvard Business School Press.

Ibarra, H., Carter, N.M., \& Silva, C. (2010). Why men still get more promotions than women. Harvard Business Review.

Ibarra, H., Ely, R.J., \& Kolb, D.M. (2013). Women rising: The unseen barriers. Harvard Business Review, 91(9), 62-67.

Judge, T.A., \& Piccolo, R.F. (2004). Transformational and transactional leadership: A meta-analytic test of their relative validity. Journal of Applied Psychology, 89(5), 755-768. https://doiorg.ccl.idm.oclc.org/10.1037/0021-9010.89.5.755

Koenig, A.M., Eagly, A.H., Mitchell, A.A., \& Ristikari, T. (2011). Are leader stereotypes masculine? A meta-analysis of three research paradigms. Psychological Bulletin, 137(4), 616-642. https://doi.org/10.1037/a0023557

Kirkpatrick, D.L. (1959). Techniques for evaluating training programs. Journal of the American Society of Training Directors, 13, 3-9.

Lacerenza, C.N., Reyes, D.L., Marlow, S.L., Joseph, D.L., \& Salas, E. (2017). Leadership training design, delivery, and implementation: A meta-analysis. Journal of Applied Psychology, 102(12), 16861718. https://doi.org/10.1037/ap10000241

Latu, I.M., Mast, M.S., Bombardi, D., Lammers, J., \& Hoyt, C.L. (2019). Empowering mimicry: Female leader role models empower women in leadership tasks through body posture mimicry. Sex Roles, 80, 11-24. https://doi.org/10.1007/s11199-018-0911-y

Lowe, K.B., Kroeck, K.G., \& Sivasubramaniam, N. (1996). Effectiveness correlates of transformation and transactional leadership: A meta-analytic review of the MLQ literature. The Leadership Quarterly, 7(3), 385-425. https://doi-org.ccl.idm.oclc.org/10.1016/S1048-9843(96)90027-2

Luthans, F., Peterson, S.J., \& Ibrayeva, E. (1998). The potential for the "dark side" of leadership in postcommunist countries. Journal of World Business, 33(2), 185-201. https://doi.org/10.1016/S10909516(98)90005-0

Madgavkar, A., White, O., Krishnan, M., Mahajan, D., \& Azcue, X. (2020). COVID-19 and gender equality: Countering the regressive effects. McKinsey \& Company.

McCall, M.W., Jr. (2010). Recasting leadership development. Industrial and Organizational Psychology: Perspectives on Science and Practice, 3(1), 3-19. https://doi-org.ccl.idm.oclc.org/10.1111/j.17549434.2009.01189.x

Murphy, W.M., Gibson, K.R., \& Kram, K.E. (2017). Advancing women through developmental relationships. In S.R. Madsen (Ed.), Handbook of Research on Gender and Leadership (pp. 361377). Edward Elgar Publishing.

Murphy, S.E., \& Johnson, S.K. (2011). The benefits of a long-lens approach to leader development: Understanding the seeds of leadership. The Leadership Quarterly, 22(3), 459-470. https://doiorg.ccl.idm.oclc.org/10.1016/j.leaqua.2011.04.004

Noe, R.A. (2019). Employee Training and Development (8th Edition). McGraw-Hill Irwin.

Olsson, M., \& Martiny, S.E. (2018). Does exposure to counter-stereotypical role models influence girls' and women's gender stereotypes and career choices? A review of social psychological research. Frontiers in Psychology, 9, 1-15. https://doi.org/10.3389/fpsyg.2018.02264 
Patel, L. (2010). Overcoming barriers and valuing evaluation. Training and Development, 64(2), 62-63.

Paustian-Underdahl, S.C., Walker, L.S., \& Woehr, D.J. (2014). Gender and perceptions of leadership effectiveness: A meta-analysis of contextual moderators. Journal of Applied Psychology, 99(6), 1129-1145. https://doi.org/10.1037/a0036751

Petriglieri, G., \& Petriglieri, J.L. (2010). Identity workspaces: The case of business schools. Academy of Management Learning and Education, 9(1), 44-60. https://doi.org/10.5465/amle.9.1.zqr44

Powell, G.N., Butterfield, A.D., \& Parent, J.D. (2002). Gender and managerial stereotypes: Have the times changed? Journal of Management, 28(2), 177-193. https://doi.org/10.1177/014920630202800203

Powell, K.S., \& Yalcin, S. (2010). Managerial training effectiveness: A meta-analysis 1952-2002. Personnel Review, 39(2), 227-241. https://doi.org/10.1108/00483481011017435

Reichard, R.J., \& Beck, J.E. (2017). Leader developmental readiness: Deconstructed and reconstructed. In M.G. Clark (Ed.), Leader Development Deconstructed, Annals of Theoretical Psychology. Switzerland: Springer International.

Reichard, R.J., Serrano, S.A., Condren, M., Wilder, N., Dollwet, M., \& Wang, W. (2015). Engagement in cultural trigger events in the development of cultural competence. Academy of Management Learning \& Education, 14(4), 461-481. https://doi.org/10.5465/amle.2013.0043

Reichard, R.J., Trainor, L.L., Jensen, K.L., \& Alonso, I.M. (2020). Women's leadership across cultures: Intersections, barriers, and leadership development. In F.M. Cheung \& D.F. Halpern (Eds.), The Cambridge Handbook of the International Psychology of Women.

Ridgeway, C.L. (1997). Interaction and the conservation of gender inequality: Considering employment. American Sociological Review, 62(2), 218-235. https://doi-org.ccl.idm.oclc.org/10.2307/2657301

Schein, V.E., \& Davidson, M.J. (1993). "Think-manager-think-male": Managerial sex typing among U.K. busines students. Management Development Review, 6, 24-28. https://doi.org/10.1108/EUM0000000000738

Schein, E.H. (1990). Organizational culture. American Psychological Association, 45, 109-119. https://doi.org/10.1037/0003-066X.45.2.109

Shamir, B., \& Eilam, G. (2005). "What's your story?” A life-stories approach to authentic leadership development. The Leadership Quarterly, 16(3), 395-417. https://doi.org.ccl.idm.oclc.org/10.1016/j.leaqua.2005.03.005

Sosik, J.J., \& Jung, D. (2018). Full range leadership development: Pathways for people, profit, and planet. Routledge. https://doi.org/10.4324/9781315167206

Sugiyama, K., Cavanagh, K.V., van Esch, C., Bilimoria, D., \& Brown, C. (2016). Inclusive leadership development: Drawing from pedagogies of women's and general leadership development programs. Journal of Management Education, 40(3), 253-292. https://doi.org/10.1177/1052562916632553

Szell, M., \& Thurner, S. (2013). How women organize social networks different from men. Scientific Reports, 3, 1214-1222. https://doi.org/10.1038/srep01214

Trainor, L. (2021). The role of organizational structure in women's leadership journeys: A framework for analysis. Claremont Graduate University, Unpublished Review Paper.

Van, V.E., McCauley, C.D., Ruderman, M.N., \& Center for Creative Leadership. (2010). The Center for Creative Leadership handbook of leadership development. Jossey-Bass.

Vogel, B., Reichard, R.J., Batistič, S., \& Černe, M. (2020). A bibliometric review of the leadership development field: How we got here, where we are, and where we are headed. The Leadership Quarterly. https://doi-org.ccl.idm.oclc.org/10.1016/j.leaqua.2020.101381

Wang, S., Yi, X., Lawler, J., \& Zhang, M. (2011). Efficacy of high-performance work practices in Chinese companies. The International Journal of Human Resource Management, 22(11), 2419 2441. https://doi-org.ccl.idm.oclc.org/10.1080/09585192.2011.584406

Weiss, C.H. (1997). Evaluation (2nd Edition). Prentice Hall. 
Wilson, M.S., \& Yip, J. (2010). Grounding leader development: Cultural perspectives. Industrial and Organizational Psychology: Perspectives on Science and Practice, 3(1), 52-55. https://doiorg.ccl.idm.oclc.org/10.1111/j.1754-9434.2009.01198.x

Yip, J., Trainor, L., Black, H. Soto, L., \& Reichard, R.J. (2020). Coaching new leaders: A relational process of integrating multiple identities. Academy of Management Learning \& Education, 19(4), 503-520. https://doi.org/10.5465/amle.2017.0449

Zheng, W., Kark, R., \& Meister, A.L. (2018). Paradox versus dilemma mindset: A theory of how women leaders navigate the tensions between agency and communion. The Leadership Quarterly, 29, 584-596. https://doi.org/10.1016/j.leaqua.2018.04.001 